\title{
Association between modelled traffic- related air pollution and asthma score in the
} ECRHS

\author{
B. Jacquemin*,\#, J. Sunyer*, $\uparrow_{,+, \S}$, B. Forsberg ${ }^{f}$, I. Aguilera*, ${ }^{*,+}$, L. Bouso*, ${ }^{*},+$, \\ D. Briggs**, R. de Marco ${ }^{\# \#, ~ R . ~ G a r c i ́ a-E s t e b a n *, ~}{ }^{*+}$, J. Heinrich ${ }^{\%}$, D. Jarvis ${ }^{++}$, \\ J.A. Maldonado ${ }^{\S \S}$, F. Payo ${ }^{f f}$, E. Rage ${ }^{\#}$, D. Vienneau ${ }^{\star *}$ and N. Künzli, ${ }^{* \sigma_{,},+* * *}$
}

ABSTRACT: The aim of our analysis was to study the association between air pollution and asthma among adults. For this goal, a previously developed "asthma score" was used.

Persons aged 25-44 yrs were randomly selected (1991-1993) and followed up (2000-2002) within the European Community Respiratory Health Survey (ECRHS I and II, respectively). The asthma score was defined from 0 to 5 , based on the positive answers to the following symptoms reported for the last 12 months: wheeze/breathlessness, chest tightness, dyspnoea at rest, dyspnoea after exercise and woken by dyspnoea. Participants' home addresses were linked to outdoor modelled $\mathrm{NO}_{2}$ estimates for 2001. Negative binomial regression was used to model the asthma score.

The score from ECRHS II was positively associated with $\mathrm{NO}_{2}$ (ratio of the mean asthma score (RMS) 1.23 , 95\% Cl 1.09-1.38, for an increase of $10 \mu \mathrm{g} \cdot \mathrm{m}^{-3}$ ). After excluding participants with asthma and symptoms at baseline, the association remained (RMS 1.25, 95\% Cl 1.05-1.51), and was particularly high among those reporting a high score in ECRHS II. The latter probably reflects incident cases of asthma.

Our results suggest that traffic-related pollution causes asthma symptoms and possibly asthma incidence in adults. The asthma score offers an alternative with which to investigate the course and aetiology of asthma in adults.

KEYWORDS: Air pollution, asthma, asthma score

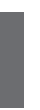
$\mathrm{t}$ is well known from time-series and other studies that fluctuations in air pollution levels are associated with short-term effects among asthmatics [1]. Evidence of adverse effects of air pollution on asthma outcomes and of a potential asthmogenic role of traffic-related local pollutants are studied far more frequently in children than in adults [2-4]. In adults, trafficrelated pollutants have been associated with cough, bronchitis and chronic obstructive pulmonary disease (COPD) [5-7], and living close to a major road has been associated with asthmarelated symptoms [8]. An Italian study found indications of an association between nitrogen dioxide $\left(\mathrm{NO}_{2}\right)$ and asthma prevalence in young adults when stratified by different climates [9]. US veterans residing near a major road had higher prevalence of persistent wheeze [10]. One study found that healthcare use for asthma in adults was associated with traffic volume [11]. In a recent study, MC CREANOR et al. [12] reported that exposure to road-traffic air pollution levels was associated with a decrease in lung function and with an increase in biomarkers of neutrophilic inflammation in asthmatics adults. Air pollutants may amplify the inflammatory reactions in the airways but, in addition, promote allergic disease in asthmatics [13-15]. Pollutantinduced oxidative stress could promote airway inflammation and, therefore, hyperresponsiveness, which may be one path to the development of asthma.

The European Community Respiratory Health Survey (ECRHS) has found a positive association between $\mathrm{NO}_{2}$ and asthma incidence in adulthood [16]. In that analysis, "asthma incidence" was defined in the traditional way, assuming asthma to be a well-defined dichotomous phenotype with a specified time of onset ("doctor-diagnosed asthma"). However, as previously promoted, asthma can be defined as a continuous trait using a grading scheme based on reported symptoms $[17,18]$. Markers of asthma severity and major

\section{AFFILIATIONS}

${ }^{*}$ Centre for Research in

Environmental Epidemiology (CREAL),

"Municipal Institute of Medical Research (IMIM)-Hospital del Mar, ${ }^{+} \mathrm{CIBER}$ in Epidemiology and Public Health (CIBERESP),

${ }^{\S}$ Dept of Health and Experimental Sciences, University Pompeu Fabra, ${ }^{* * *}$ Catalan Institution for Research and Advanced Studies, ICREA, Barcelona,

${ }^{\S \S}$ Hospital Juan Ramon Jimenez, Huelva, and

${ }^{f f} \mathrm{H}$ ospital Central de Asturias,

Oviedo, Spain.

\# INSERM U780, Epidemiology and Biostatistics, University Paris-Sud, Villejuif, France.

${ }^{f}$ Occupational and Environmental Medicine, Dept of Public Health and Clinical Medicine, Umeå University, Umeå, Sweden.

**Dept of Respiratory Epidemiology and Public Health, Imperial College,

${ }^{++}$National Heart and Lung Institute,

Imperial College London, London, UK. \#\# Dept of Medicine and Public

Health, University of Verona, Verona, Italy.

"Institute of Epidemiology,

Helmholtz Zentrum München, Munich, Germany.

CORRESPONDENCE

B. Jacquemin, Inserm U780,

Epidémiologie et Biostatistique, 16, avenue Paul Vaillant Couturier

E-mail: benedicte.jacquemin@

inserm.fr

Received:

Sept 092008

Accepted after revision:

April 232009

First published online:

May 142009

European Respiratory Journal

Print ISSN 0903-1936

Online ISSN 1399-3003 
risk factors of asthma showed a significant linear association with this novel asthma score. Using a continuous measure of a complex disease has some appeal as it improves the power to identify risk factors. The score is also not affected by diagnostic practices, which may vary grossly between regions and also over time within the same area [18]. The aim of our study was to explore the association between the asthma score and trafficrelated air pollution estimated at follow-up. The concept of asthma taken as a continuous trait is rather novel and has not yet been explored in air pollution epidemiology, thus, the utility and possible interpretations of the score in this field will be discussed.

\section{METHODS}

\section{Study population}

The details of the present study are described elsewhere $[19,20]$. Briefly, persons aged 25-44 yrs were randomly selected from the population for the ECRHS I carried out during 1991-1993 [20]. The follow-up (ECRHS II) took place during the period 2000-2002 (mean response rate 65.3\%) [19]. Both surveys included an initial screening questionnaire, an extensive interviewer-led questionnaire, a skin prick test, a blood test for immunoglobulin E, spirometry and a methacholine challenge test. Ethical approval was obtained for each centre from the appropriate institutional or regional ethics committee, and written consent was obtained from each participant. From the 25 cities (8,090 participants from the random sample) included in ECRHS II, 20 (6,824 participants) had central air pollution data. Three of those cities were not included in the Air Pollution Modelling for Support to Policy on Health and Environmental Risk in Europe (APMoSPHERE) project (Reykjavik (Iceland), Tartu (Estonia) and Basel (Switzerland), $n=1,178)$. Erfurt, Germany $(n=282)$, was excluded due to participant identifier linkage problems occurring during the geocoding procedure while protecting confidentiality of the participants' address data. In total, 4,394 participants from the random sample had information on the asthma score and home outdoor modelled $\mathrm{NO}_{2}$ at follow-up and 2,921 participants had full information on all the covariates included in the final multivariate analysis.

\section{Asthma score}

The asthma score used in our study is one of the two previously developed [18] scores using data from ECRHS [17]. Two scores were proposed, one based on answers to eight questions (where three included the term "asthma") and another based on positive answers to just the five questions dealing only with symptoms. The five symptoms were as follows: wheeze and breathlessness, feeling of chest tightness, attack of shortness of breath at rest, attack of shortness of breath after exercise, and woken by attack of shortness of breath during the last 12 months.

This simplified score used in this analysis ranges from $0-5$ and is independent of local trends in "asthma labelling" [18].

\section{Covariates}

We included in the analysis the following variables collected through a standardised questionnaire: sex, age, social class (in five groups based on the International Standard Classification of Occupations coding of the occupational history at ECRHS II and derived from the longest-held job during the follow-up period between ECRHS I and II), family history of asthma or atopy, smoking (no, former or current), pack-years, exposure to second-hand tobacco smoke, any exposure to dust, fume or gases at work, gas cooking and season of the interview.

We also included atopy defined as a concentration $>0.35 \mathrm{kU} \mathrm{A} \cdot \mathrm{L}^{-1}$ for any specific immunoglobulin $\mathrm{E}$ to cat $(\mathrm{e} 1)$, house dust mites (Dermatophagoides pteronyssinus $\mathrm{d} 1$ ), Cladosporidium as indicator of mould (g6) or timothy grass determined using the Pharmacia CAP system (Pharmacia, Uppsala, Sweden).

Finally, bronchial hyperresponsiveness (BHR) and \% predicted forced expiratory volume in $1 \mathrm{~s}$ (FEV1) were also taken into account. BHR to methacholine was measured in eligible participants using one of two dosing schedules, one delivering methacholine to a maximum dose of $1 \mathrm{mg}$ and the other to a maximum of $2 \mathrm{mg}$. Methacholine was delivered via a Mefar dosimeter (Mefar, Bovezzo, Italy), recorded 2 min after each inhalation and the test terminated when either a $20 \%$ fall in FEV1 had been achieved or the final dose given.

\section{Modelled $\mathrm{NO}_{2}$ concentrations with APMoSPHERE}

$\mathrm{NO}_{2}$ has been widely used in epidemiological studies as a marker for traffic-related air pollution [21-23]. As part of the APMoSPHERE project [24], 1-km resolution emission maps were developed for the then 15 member states by disaggregating national emissions estimates, categorised by sources of air pollution, on the basis of relevant proxies including population density, road distribution and land cover. The $\mathrm{NO}_{\mathrm{x}}$ emission map was then used as the basis for modelling mean annual $\mathrm{NO}_{2}$ concentrations using focal sum techniques, in a geographical information system. The model provides estimates of concentrations by calibrating the distanceweighted sum of the emissions (tonnes $\cdot \mathrm{km}^{-1} \cdot \mathrm{yr}^{-1}$ ) in concentric rings (annuli) around each monitoring site to the monitored concentrations $\left(\mu \mathrm{g} \cdot \mathrm{m}^{-3}\right)$. Models were developed using monitoring data from the European Union Airbase database. Models were calibrated using 714 background sites for 2001, and validated by comparing predictions with observations for a separate set of 228 reserved background sites $\left(r^{2}=0.60\right)$.

Participant's residential addresses were geocoded manually using an online mapping service (www.multimap.com). $\mathrm{NO}_{2}$ at the place of residence of each participant at follow-up (ECRHS II) was obtained by intersecting the geographical coordinates of the address with the map of $\mathrm{NO}_{2}$ concentrations.

\section{Statistical analysis}

Due to the score distribution, i.e. being a scale with a majority of zeros, the negative binominal regression model (with a log link), which allows for extra-Poisson variation, is the most appropriate for modelling this score [25]. The results are expressed as ratios of the mean asthma scores (RMS). For $\mathrm{NO}_{2}$ the effect for an increase of a $10 \mu \mathrm{g} \cdot \mathrm{m}^{-3}$ higher concentration is reported, corresponding approximately to the difference between the 5th and the 95th percentiles in the city with lower levels of $\mathrm{NO}_{2}$ (Umeå, Sweden).

In a first step, we analysed the score cross-sectionally; thus, in all the participants and adjusting for follow-up characteristics, we analysed the association of $\mathrm{NO}_{2}$ with the score at ECRHS II. 


\begin{tabular}{|c|c|c|c|c|c|c|c|c|c|c|c|}
\hline & Participants $\mathrm{n}$ & \multicolumn{2}{|c|}{ Score at ECRHS I } & \multicolumn{2}{|c|}{ Score at ECRHS II } & \multicolumn{6}{|c|}{$\mathrm{NO}_{2}$ percentiles ${ }^{\#}$} \\
\hline Umeå & 147 & 80 & $0.39 \pm 0.97$ & 79 & $0.4 \pm 0.97$ & 8 & 11 & 12 & 14 & 17 & 19 \\
\hline Uppsala & 478 & 79 & $0.39 \pm 0.91$ & 77 & $0.45 \pm 1$ & 9 & 11 & 16 & 20 & 33 & 43 \\
\hline Norwich & 224 & 66 & $0.71 \pm 1.24$ & 65 & $0.64 \pm 1.08$ & 17 & 23 & 25 & 27 & 29 & 33 \\
\hline Ipswich & 239 & 78 & $0.53 \pm 1.17$ & 59 & $0.75 \pm 1.09$ & 19 & 25 & 26 & 28 & 32 & 33 \\
\hline Antwerp & 633 & 71 & $0.49 \pm 0.94$ & 75 & $0.43 \pm 0.89$ & 19 & 23 & 28 & 33 & 36 & 39 \\
\hline Paris & 416 & 52 & $0.85 \pm 1.18$ & 58 & $0.7 \pm 1.04$ & 19 & 49 & 50 & 53 & 54 & 55 \\
\hline Grenoble & 380 & 69 & $0.52 \pm 0.95$ & 66 & $0.59 \pm 1.02$ & 12 & 25 & 31 & 31 & 32 & 55 \\
\hline Verona & 281 & 90 & $0.14 \pm 0.44$ & 79 & $0.34 \pm 0.82$ & 16 & 24 & 28 & 29 & 32 & 34 \\
\hline Barcelona & 250 & 79 & $0.32 \pm 0.73$ & 73 & $0.46 \pm 0.88$ & 30 & 53 & 57 & 59 & 62 & 63 \\
\hline Albacete & 140 & 61 & $0.76 \pm 1.2$ & 59 & $0.71 \pm 1.03$ & 18 & 28 & 30 & 32 & 32 & 32 \\
\hline Huelva & 204 & 74 & $0.52 \pm 1.04$ & 56 & $0.83 \pm 1.23$ & 26 & 30 & 33 & 34 & 35 & 44 \\
\hline Total & 4394 & 72 & $0.49 \pm 0.99$ & 70 & $0.52 \pm 0.98$ & 11 & 21 & 28 & 33 & 54 & 63 \\
\hline
\end{tabular}

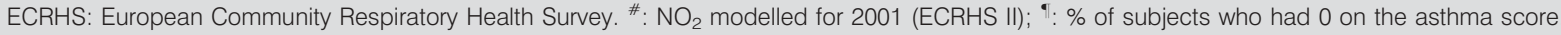

The data was analysed when pooled for all the centres, but was adjusted by centre. We report the crude association adjusted only by centre. We then conducted a multivariate analysis retaining all variables significantly associated with the score in the crude model in order to achieve a parsimonious model. Age was forced into the model. Effect estimates were derived for each centre and heterogeneity across the city-specific estimates was examined by using standard methods for random-effects meta-analysis [26, 27]. A random-effect metaanalysis was also performed by geographical region: North (Sweden), Centre (Belgium, England, France) and South (Spain, Italy). The analyses were stratified by sex, asthma, atopy, BHR and smoking status, all defined at baseline. The stratified models included all the above covariates except the stratification variable. Wald tests were performed to test the interactions between the variable used for the stratification and the $\mathrm{NO}_{2}$ and associated p-values were calculated.

In a second step, we studied the association between the score and $\mathrm{NO}_{2}$ concentration, both defined at follow-up, in a subpopulation reporting neither symptoms nor asthma at baseline. The same multivariate model and data pooling was adopted as in the first step mentioned above. This population may be considered a sample being in all likelihood free of asthma at baseline. Thus, the occurrence of symptoms at follow-up may be interpreted as new onset of symptoms, which may ultimately reflect incidence of asthma. While this notion may be questionable among those reporting only one symptom at ECRHS II, a high asthma score may reflect new onset of asthma. Thus we performed a further analysis considering those with none or only one symptom at followup as participants free of symptoms and we compared them with participants reporting at least two symptoms. Next we considered those reporting none, one or two symptoms as participants free of symptoms, comparing them with participants reporting at least three symptoms.

The analyses were made using STATA 8 (StatCorp LP, College Station, TX, USA). The criterion for statistical significance was set at a $\mathrm{p}$-value $<0.05$.

\section{RESULTS}

The study includes 4,394 participants with both data on asthma and modelled $\mathrm{NO}_{2}$ concentration, used as a marker of trafficrelated ambient air pollution. The distribution of the asthma score was skewed: $70 \%$ of the study participants reported none of the asthma symptoms and scored 0 . The mean score was 0.52 and the standard deviation 0.98. Table 1 shows the distribution of the score and $\mathrm{NO}_{2}$ by city ordered from northernmost to southernmost.

Table 2 describes the distribution of the covariates. Of the participants, $55 \%$ are females. The distribution of the covariates between ECRHS I and II did not vary except for smoking, with a decrease of smokers in ECRHS II.

The crude association between the covariates and the score is shown in table 3. Season and any exposure to gas, dust or fumes at work were not associated with the score. The RMS for each increase of $10 \mu \mathrm{g} \cdot \mathrm{m}^{-3}$ of $\mathrm{NO}_{2}$ is 1.15 (95\% CI 1.05-1.25).

In the multivariate analysis, the RMS for each increase of $10 \mu \mathrm{g} \cdot \mathrm{m}^{-3}$ of $\mathrm{NO}_{2}$ was 1.23 (95\% CI 1.09-1.38; table 4).

The association was homogeneous among centres $(p=0.169)$; after excluding Turin, which had very large confidence intervals, the p-value for heterogeneity was still not significant $(p=0.244)$ (fig. 1). We did not observe heterogeneity across the three geographical areas ( $p$-value of homogeneity 0.947) (fig. 2). 


\begin{tabular}{|c|c|c|c|}
\hline \multirow[t]{2}{*}{ TABLE 2} & \multicolumn{3}{|c|}{$\begin{array}{l}\text { Characteristics of the participants at European } \\
\text { Community Respiratory Health Survey (ECRHS) I } \\
\text { and II }\end{array}$} \\
\hline & & ECRHS I & ECRHS II \\
\hline \multicolumn{2}{|l|}{ Participants } & $4394(100)$ & $4394(100)$ \\
\hline \multicolumn{2}{|l|}{ Females } & $2433(55)$ & $2433(55)$ \\
\hline \multicolumn{4}{|l|}{ Age yrs } \\
\hline \multicolumn{2}{|l|}{$\leqslant 30$} & 1467 (33) & $N A^{\#}$ \\
\hline \multicolumn{2}{|l|}{ 30-35 } & 864 (19) & $777(17)$ \\
\hline \multicolumn{2}{|l|}{$35-40$} & $922(21)$ & $897(20)$ \\
\hline \multicolumn{2}{|l|}{$40-45$} & $1019(23)$ & $879(20)$ \\
\hline \multicolumn{2}{|l|}{$45-50$} & $200(4)$ & $926(21)$ \\
\hline \multicolumn{2}{|l|}{$>50$} & $N A^{\#}$ & $998(22)$ \\
\hline \multicolumn{4}{|c|}{ Social class at ECRHS II" } \\
\hline \multicolumn{2}{|c|}{ Managers and professionals (I-II) nonmanual } & $N A^{\#}$ & $1230(27)$ \\
\hline \multicolumn{2}{|c|}{ Others (III) nonmanual } & $N A^{\#}$ & $1912(43)$ \\
\hline \multicolumn{2}{|c|}{ Skilled (III) manual } & $N A^{\#}$ & $388(9)$ \\
\hline \multicolumn{2}{|c|}{ Semi-skilled or unskilled manual (IV-V) } & $N A^{\#}$ & $446(10)$ \\
\hline \multicolumn{2}{|c|}{ Unclassified or unknown } & $N A^{\#}$ & $501(11)$ \\
\hline \multicolumn{2}{|l|}{ Atopy } & $1046(29)$ & 995 \\
\hline \multicolumn{2}{|c|}{ Family history of asthma or atopy } & $1533(37)$ & $1533(37)$ \\
\hline \multicolumn{4}{|l|}{ Smoking } \\
\hline \multicolumn{2}{|l|}{ Never } & $1967(44)$ & $1931(43)$ \\
\hline \multicolumn{2}{|l|}{ Former } & $984(22)$ & $1275(29)$ \\
\hline \multicolumn{2}{|l|}{ Current } & $1523(34)$ & $1260(28)$ \\
\hline \multicolumn{2}{|c|}{ Smoking pack-years } & $\mathrm{NA}^{+}$ & $11 \pm 17$ \\
\hline \multicolumn{2}{|c|}{ Exposure to second-hand tobacco smoke } & $2622(59)$ & $1825(41)$ \\
\hline \multicolumn{2}{|l|}{ FEV 1 \% pred } & $108 \pm 13$ & $108 \pm 14$ \\
\hline \multicolumn{4}{|c|}{$\begin{array}{l}\text { Data are presented as } n(\%) \text { or mean } \pm \mathrm{SD} \text {. NA: not applicable; FEV1: forced } \\
\text { expiratory volume in } 1 \mathrm{~s} \text {; \% pred: \% predicted. }{ }^{\#} \text { : due to the design of the study; } \\
\text { : social class was produced with two different methods at both surveys; social } \\
\text { class at ECRHS II took into account the longest-held job during the follow-up } \\
\text { period between ECRHS I and II; }{ }^{+} \text {: only available for ECRHS II. }\end{array}$} \\
\hline
\end{tabular}

After stratifying for baseline characteristics, all the associations were always positive, but the RMS was higher in males, nonasthmatics, atopics, participants with BHR and in nonsmokers and ex-smokers (table 5). However, only the p-value for interaction for smoking was significant (RMS in nonsmokers and ex-smokers: 1.30, 95\% CI 1.11-1.52; RMS in smokers: 1.07, 95\% CI 0.92-1.26; p-value for interaction: 0.005).

In participants with no asthma and no symptoms at baseline, the associations between $\mathrm{NO}_{2}$ and asthma score were positive (RMS $1.25,95 \%$ CI 1.05-1.50). When comparing participants reporting none or one symptom with those reporting a score $\geqslant 2$, the effect estimates increased (RMS 1.45, 95\% CI 1.03-2.05). The association became even higher when considering participants reporting a score $\geqslant 3$ (RMS 2.57, 95\% CI 1.31-5.04; table 5).

\section{DISCUSSION}

We observed significant associations between traffic-related air pollution and the asthma score, with similar findings across Europe.

To put the findings into context, we refer to table 4 , which shows that a rather modest change in $\mathrm{NO}_{2}$ of only $10 \mu \mathrm{g} \cdot \mathrm{m}^{-3}$

\begin{tabular}{|c|c|c|}
\hline \multirow[t]{2}{*}{ TABLE 3} & \multicolumn{2}{|c|}{$\begin{array}{l}\text { Crude association (adjusted for centre only) } \\
\text { between asthma score (five items) at follow-up } \\
\text { and follow-up characteristics in all the } \\
\text { participants, expressed in the ratio of mean } \\
\text { asthma score (RMS) }\end{array}$} \\
\hline & & RMS (95\% Cl) \\
\hline \multicolumn{2}{|c|}{$\mathrm{NO}_{2}$ (per each increase of $10 \mu \mathrm{g} \cdot \mathrm{m}^{-3}$ ) } & $1.15(1.05-1.25)$ \\
\hline \multicolumn{2}{|l|}{ Females } & $1.19(1.06-1.34)$ \\
\hline \multicolumn{3}{|c|}{ Age at ECRHS II yrs } \\
\hline \multicolumn{2}{|l|}{$\leqslant 35$} & 1.00 \\
\hline \multicolumn{2}{|l|}{$35-40$} & $1.12(0.93-1.35)$ \\
\hline \multicolumn{2}{|l|}{$40-45$} & $0.97(0.80-1.18)$ \\
\hline \multicolumn{2}{|l|}{$45-50$} & $0.94(0.78-1.14)$ \\
\hline \multicolumn{2}{|l|}{$>50$} & $0.95(0.78-1.14)$ \\
\hline \multicolumn{3}{|c|}{ Social class at ECRHS $\|^{\#}$} \\
\hline \multicolumn{2}{|c|}{$|-| \mid$} & 1.00 \\
\hline \multicolumn{2}{|c|}{ III nonmanual } & $1.27(1.10-1.46)$ \\
\hline \multicolumn{2}{|l|}{ III manual } & $0.97(0.76-1.23)$ \\
\hline \multicolumn{2}{|l|}{ IV-V } & $1.43(1.16-1.77)$ \\
\hline \multicolumn{2}{|l|}{ Unclassified } & $1.16(0.94-1.43)$ \\
\hline \multicolumn{2}{|c|}{ Atopy at ECRHS II } & $1.69(1.48-1.94)$ \\
\hline \multicolumn{2}{|c|}{ Family history of asthma or atopy } & $1.50(1.32-1.70)$ \\
\hline \multicolumn{3}{|c|}{ Smoking at ECRHS II } \\
\hline \multicolumn{2}{|l|}{ Never } & 1.00 \\
\hline \multicolumn{2}{|l|}{ Former } & $1.15(1.00-1.32)$ \\
\hline \multicolumn{2}{|l|}{ Current } & $1.52(1.33-1.75)$ \\
\hline \multicolumn{2}{|c|}{ Smoking pack-yrs } & $1.01(1.01-1.01)$ \\
\hline \multicolumn{2}{|c|}{$\begin{array}{l}\text { Exposure to second-hand tobacco smoke at } \\
\text { ECRHS II }\end{array}$} & $1.39(1.23-1.57)$ \\
\hline \multicolumn{2}{|c|}{ FEV1 at ECRHS II \% pred } & $0.98(0.97-0.98)$ \\
\hline \multicolumn{2}{|c|}{ Cooking done mainly with gas } & $1.07(0.93-1.24)$ \\
\hline \multicolumn{2}{|c|}{ Occupational exposure to dust, fumes or gases } & $0.98(0.90-1.07)$ \\
\hline \multicolumn{3}{|c|}{ Season of the interview } \\
\hline \multicolumn{2}{|l|}{ Spring } & 1.00 \\
\hline \multicolumn{2}{|l|}{ Summer } & $1.05(0.88-1.25)$ \\
\hline \multicolumn{2}{|l|}{ Autumn } & $1.14(0.97-1.33)$ \\
\hline \multicolumn{2}{|l|}{ Winter } & $1.08(0.92-1.27)$ \\
\hline
\end{tabular}

ECRHS: European Community Respiratory Health Survey; FEV1: forced expiratory volume in $1 \mathrm{~s}$; \% pred: \% predicted. ${ }^{\#}$ : for definitions of social class, see table 2. Entries in bold are statistically significant.

resulted in a similar association to that between the asthma score and being a current smoker. A contrast of $20 \mu \mathrm{g} \cdot \mathrm{m}^{-3}$ (a difference well within the range of ambient concentrations within European cities) was associated with a difference in asthma score as strongly as a family history of asthma or atopy, which may be a good proxy for genetic factors. Our estimates are not easily comparable with other studies, as the use of this particular score is rather novel and the ratio of the mean score estimated with negative binomial regression is not directly comparable with the odds ratios obtained with logistic regression. Nevertheless, our estimates for well-known risk factors of asthma symptoms, such as smoking and a family history of asthma or atopy, are in the same range as those described in the literature. In a study among young adults, the odds ratio for asthma-like symptoms varied from 1.74 


\begin{tabular}{|c|c|c|}
\hline \multirow[t]{2}{*}{ TABLE 4} & \multicolumn{2}{|c|}{$\begin{array}{l}\text { Multivariate association (adjusted per centre) } \\
\text { between asthma score (five items) at follow-up } \\
\text { and follow-up characteristics in all the } \\
\text { participants, expressed in ratio of mean asthma } \\
\text { score (RMS) }\end{array}$} \\
\hline & & RMS $(95 \% \mathrm{Cl})$ \\
\hline \multicolumn{2}{|c|}{$\mathrm{NO}_{2}\left(\right.$ per each increase of $10 \mu \mathrm{g} \cdot \mathrm{m}^{-3}$ ) } & $1.23(1.09-1.38)$ \\
\hline \multicolumn{2}{|l|}{ Females } & $1.28(1.10-1.49)$ \\
\hline \multicolumn{3}{|c|}{ Age at ECRHS II yrs } \\
\hline \multicolumn{2}{|l|}{$\leqslant 35$} & 1.00 \\
\hline \multicolumn{2}{|l|}{$35-40$} & $1.14(0.91-1.43)$ \\
\hline \multicolumn{2}{|l|}{$40-45$} & $1.02(0.81-1.29)$ \\
\hline \multicolumn{2}{|l|}{$45-50$} & $1.00(0.80-1.27)$ \\
\hline \multicolumn{2}{|l|}{$>50$} & $1.13(0.89-1.42)$ \\
\hline \multicolumn{3}{|c|}{ Social class at ECRHS $\|^{\#}$} \\
\hline \multicolumn{2}{|c|}{ I-II } & 1.00 \\
\hline \multicolumn{2}{|c|}{ III nonmanual } & $1.18(1.00-1.39)$ \\
\hline \multicolumn{2}{|l|}{ III manual } & $0.95(0.71-1.26)$ \\
\hline \multicolumn{2}{|l|}{ IV-V } & $1.28(0.99-1.65)$ \\
\hline \multicolumn{2}{|l|}{ Unclassified } & $1.28(0.96-1.69)$ \\
\hline \multicolumn{2}{|c|}{ Atopy at ECRHS II } & $1.64(1.42-1.89)$ \\
\hline \multicolumn{2}{|c|}{ Family history of asthma or atopy } & $1.40(1.22-1.61)$ \\
\hline \multicolumn{3}{|c|}{ Smoking at ECRHS II } \\
\hline \multicolumn{2}{|l|}{ Never } & 1.00 \\
\hline \multicolumn{2}{|l|}{ Former } & $1.17(0.98-1.40)$ \\
\hline \multicolumn{2}{|l|}{ Current } & $1.27(1.04-1.56)$ \\
\hline \multicolumn{2}{|c|}{ Smoking pack-years } & $1.00(1.00-1.01)$ \\
\hline \multicolumn{2}{|c|}{ Exposure to second-hand tobacco smoke at ECRHS II } & $1.23(1.06-1.43)$ \\
\hline \multicolumn{2}{|c|}{ FEV 1 at ECRHS II \% pred } & $0.98(0.97-0.98)$ \\
\hline
\end{tabular}

ECRHS: European Community Respiratory Health Survey; FEV1: forced expiratory volume in $1 \mathrm{~s}$; \% pred: \% predicted. ${ }^{\#}$ : for definitions of social class, see table 2. Entries in bold are statistically significant.

(shortness of breath) to 3 (wheezing) for smoking [28]. In a study conducted in Northern Europe, the odds ratio of presenting wheezing in the last 12 months ranged from 1.53.6 depending on the intensity of smoking. In the same study, the odds ratio for wheezing in the last 12 months was 2.24 for family history of asthma [29]. Regarding air pollution, an increase of almost $20 \mu \mathrm{g} \cdot \mathrm{m}^{-3}$ in $\mathrm{NO}_{2}$ levels was moderately associated with tightness in the chest (OR 1.11) and wheeze (OR 1.11) in an Italian study [9]. In a Swedish study, $\mathrm{NO}_{2}$ values $>19 \mu \mathrm{g} \cdot \mathrm{m}^{-3}$ measured at the address were associated with a moderate increase in asthma symptoms (OR 1.21) [30]. Our air pollution estimates seem higher than those previously described, but the association between air pollution and asthma symptoms in adults has not been frequently studied and comparability with the score is limited.

The score comes with several advantages as compared with a dichotomous definition of asthma. As previously shown, it may be a valuable instrument to reduce misclassification bias due to dichotomisation of asthma [17, 18]. The use of a continuous measure increases the power to detect risk factors, a notion supported by our findings. The use of a score is a novel approach not only to characterise asthmatic symptoms, but also as an approach to "asthma severity" and to investigate

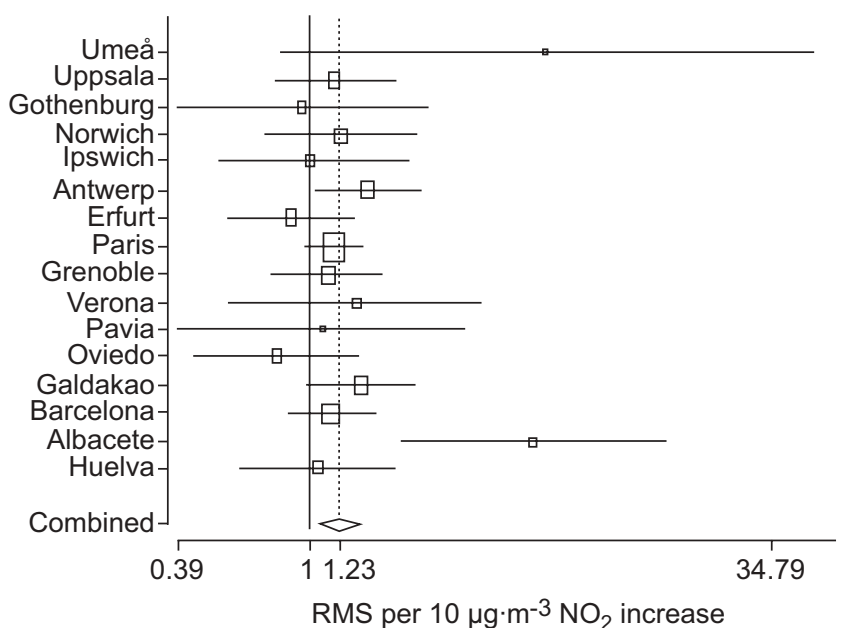

FIGURE 1. Adjusted ratio of mean asthma score (RMS) comparing the effect of $\mathrm{NO}_{2}$ per centre (after excluding Turin). $\square$ : RMS per centre, where the size of the box is proportional to the sample size of each centre; ——: $95 \% \mathrm{Cl}$ of the respective RMS; $\diamond$ : combined RMS

related risk factors [17, 18]. Furthermore, the incidence of doctor-diagnosed asthma is relatively low, requiring large studies, and the time of onset of asthma is in fact hard to define and subject to diagnostic attitudes of physicians. Moreover, asthma is a complex phenotype and the clinical severity (or symptoms) is indeed relevant for patients. Thus, to study associations between risk factors and a complex disease with all these features, the use of continuous traits is appealing. Asthma is a disease that is probably the result of a long process and it is neither easy to define the presence or absence of the disease at some definite point in time nor to identify the time of "onset" [31]. These difficulties could lead to misclassifications; the use of the symptoms-based score resolves some of the challenges faced with a dichotomous definition of asthma.

In air pollution epidemiology, the continuous score is appealing as associations with air pollution are usually low across the observed ranges of pollution, thus power is limited for disease incidence (i.e. it is either present or not). Resolving the problem of geographical variation in diagnostic patterns encountered with doctor-diagnosed asthma is particularly attractive in air pollution research where the pooling of studies, cities and countries is appealing not only to increase the power but to also investigate susceptibility factors.

However, the disadvantage of the score lies in the challenges of its interpretation, which may be the subject of continued debates, in particular in the context of air pollution research. The question emerges, as to whether the score, as used in our analyses, reflects acute effects of air pollution or its long-term chronic contribution to the underlying pathology leading to asthma incidence. We will discuss these two perspectives in more detail.

On the one hand, when asking about symptoms experienced during the last 12 months in a cross-sectional survey of the general population, the score may reflect the cumulated "acute conditions" triggered by air pollution. Among asthmatics, symptoms reflect the inherently variable phenotype of asthma; 


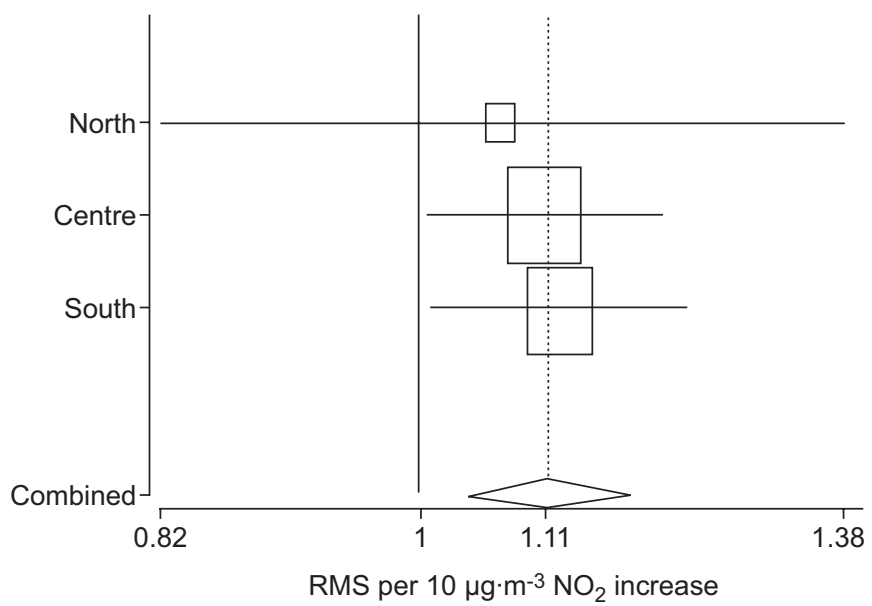

FIGURE 2. Adjusted ratio of mean asthma score (RMS) comparing the effect of $\mathrm{NO}_{2}$ per geographical area. $\square$ : RMS per region, where the size of the box is proportional to the sample size of each region; ——: $95 \% \mathrm{Cl}$ of the respective RMS; $\diamond:$ combined RMS

thus, the score may capture the course and severity/control of asthma, and our findings may be interpreted as a cumulative summary (last 12 months) of acute effects of air pollution on asthma symptoms, which may be a proxy of asthma severity. In fact, in a recent study investigating the cross-sectional relationships between asthma severity and background annual concentrations of air pollutants [32], this score was used as a marker of the activity of asthma along with another asthma severity score, both being assessed for the last 12 months. Both scores were associated with ambient home outdoor ozone concentrations, whereas no association was observed with $\mathrm{NO}_{2}$. This inconsistency may, in part, be explained by the large spatial scale of the $\mathrm{NO}_{2}$ model used in that analysis (grids of $4 \mathrm{~km}^{2}$ ) and, thus, spatial heterogeneity may not have been adequately captured.

With this interpretation of "cumulative summary", our findings are in line with the body of evidence suggesting the acute effects of air pollution [1]. The score may, thus, be used efficiently in future studies to evaluate whether acute effects of pollution on asthma performance may change in response to changes in treatments and/or in the composition of pollutants due to changes in engine technology, fuel formulation or the composition of the vehicle fleets.

On the other hand, the asthma score may also be considered as a tool to identify the incidence of asthma of various levels of severity, if we accept the notion of asthma being a continuous trait. With this interpretation, results ought to be compared with traditional "incidence studies", such as our own analysis of the ECRHS data. In that previous work, we used the dichotomised definition of new onset of doctor-diagnosed asthma. An increase of $10 \mu \mathrm{g} \cdot \mathrm{m}^{-3}$ of $\mathrm{NO}_{2}$ was associated with

\section{TABLE 5 Ratio of mean asthma score (RMS; five items) at follow-up adjusted by follow-up characteristics per each increase of} $10 \mu \mathrm{g} \cdot \mathrm{m}^{-3}$ of $\mathrm{NO}_{2}$ stratified by different groups

\begin{tabular}{|c|c|c|c|}
\hline & Subjects $n$ & RMS $(95 \% \mathrm{Cl})$ & p-value ${ }^{\#}$ \\
\hline \multicolumn{4}{|l|}{ All participants } \\
\hline Adjusted for centre & 3494 & $1.15(1.05-1.25)$ & \\
\hline Adjusted for all characteristics & 2921 & $1.23(1.09-1.38)$ & \\
\hline \multicolumn{4}{|l|}{ Sex } \\
\hline \multicolumn{4}{|l|}{ Stratified by baseline characteristics } \\
\hline Without asthma & 2696 & $1.27(1.11-1.45)$ & \\
\hline With asthma" & 224 & $1.07(0.88-1.30)$ & 0.176 \\
\hline Without atopy ${ }^{\S}$ & 1779 & $1.20(1.02-1.41)$ & \\
\hline With atopy ${ }^{\S}$ & 728 & $1.37(1.14-1.65)$ & 0.628 \\
\hline \multicolumn{4}{|l|}{ Participants with no asthma and no symptoms at baseline } \\
\hline No symptom against any symptom & $387^{\# \#}$ & $1.25(1.05-1.50)$ & \\
\hline No and one symptom against two, three, four or five symptoms" & $123^{\# \#}$ & $1.45(1.03-2.05)$ & \\
\hline No, one and two symptoms against three, four or five symptoms & $44^{\# \#}$ & $2.57(1.31-5.04)$ & \\
\hline
\end{tabular}

BHR: bronchial hyperresponsiveness, provocative dose of methacholine of $<1 \mathrm{mg}$ causing a $20 \%$ fall in forced expiratory volume in $1 \mathrm{~s}$ (FEV1). ${ }^{\#}: \mathrm{p}$-value for interaction $\because$ : adjusted for sex, age, social class, atopy, family history of atopy or asthma, smoking, exposure to second-hand tobacco smoke, \% predicted of the FEV 1 at follow-up: ${ }^{+}$: adjusted for age, social class, atopy, family history of atopy or asthma, smoking, exposure to second-hand tobacco smoke and FEV 1 ; ${ }^{\text {s: }}$ adjusted for sex, age, social class, family history of atopy or asthma, smoking, exposure to second-hand tobacco smoke and FEV1; $f_{\text {: }}$ adjusted for sex, age, social class, atopy, family history of atopy or asthma, exposure to second-hand tobacco smoke and FEV 1 ; ${ }^{\# \#}$ : number of participants with symptoms. Entries in bold are statistically significant. 
asthma incidence (OR 1.43, 95\% CI 1.02-2.01) [16]. The use of the dichotomous definition, however, presented limitations that could be overcome with the score. In adults, the definition of "asthma" remains a challenge and the score clearly complements attempts to better understand the aetiology of this disease, independent of secular trends in the labelling of "asthma" by the community of physicians. In a previous publication within the ECRHS, CHINN et al. [33] have shown that, from ECRHS I to II, the prevalence of asthma increased while the prevalence of symptoms did not, suggesting a change over time in the diagnosis or treatment of asthma. The results shown here using the asthma score are in the same direction as those we found in the previous analysis. Given the inherent variability in symptom occurrence in both asthmatics and nonasthmatics, the mere "onset" of only one symptom among those free of symptoms and asthma at baseline is unlikely to reflect incidence of asthma. This notion may be more acceptable among those presenting a high score at follow-up. Our last analysis was restricted to participants with neither asthma nor symptoms at baseline. The particularly strong effects among those presenting at least two symptoms at ECRHS II would be in line with the interpretation of an effect of pollution on onset of asthma in adults. This "incidence interpretation" of the score comes with a caveat, as SUNYER et al. [18] have shown substantial changes in the score, with many participants losing or gaining one or more symptom. As a consequence, it may be questionable to consider those with a change from no disease at baseline to a very low asthma score as "incident cases". However, a "high score" phenotype has been shown to be particularly strongly associated with doctordiagnosed asthma [18]; thus our related finding may indicate a role of pollution in new onset of asthma in adults. This interpretation is consistent with our previous finding based on the more traditional definition of "asthma incidence", using asthma at follow-up among those free of the disease at baseline [16]. That latter approach is less ambiguous in the interpretation regarding acute and chronic effects as a "doctor's diagnosis" does reflect a "chronic condition" rather the accumulated acute expression of the disease. Further research on the use and interpretation of the score as a measure of the course, and also the incidence, of this chronic disease will be useful to enhance our aetiological understanding of asthma.

We characterised exposure to pollution for approximately the same period as the assessment of the score. While a strength in the assessment and interpretation of "acute effects", the availability of air pollution measurements only for the followup period is a limitation that may affect the incidence interpretation of this analysis. Pollution levels may have changed differently across cities and participants who moved to another residence would have inherently larger misclassification of exposure. Although trends in air pollution are often spatially correlated across areas, this simplification might be less true across the very large European geographical area. However, based on network data available in several cities, one can assume that changes in air quality differed across European areas, which may bias toward null findings.

It is important to note that the association between $\mathrm{NO}_{2}$ levels and the asthma score were rather homogenous for all the cities included in this analysis. The homogeneity was even stronger when taking into account geographical area instead of city. This supports a causal interpretation of our findings.

We found a stronger effect of $\mathrm{NO}_{2}$ in nonsmokers and exsmokers compared with smokers. Smoking might be considered as an effect modifier, but previous studies have not been consistent and it remains unclear whether smokers are more or less susceptible to the effects of air pollution than nonsmokers. In the Swiss Air Pollution And Lung Disease In Adults (SAPALDIA) study, ZEMP et al. [7] found that smokers reported more asthma-like symptoms than nonsmokers, suggesting an effect modification by smoking status. It was also suggested, however, that smokers have altered lung function and an increase in mucus, which decreases the air pollutant amount in some regions of the lungs, thereby decreasing the susceptibility of smokers to air pollution [34].

The strengths and the limitations of the exposure assessment have been discussed previously [16]; by geocoding home addresses of ECRHS participants we were able to assign an ambient $\mathrm{NO}_{2}$ concentration derived from the APMoSPHERE map to each participant. Nevertheless, it is also important to take into account that the APMoSPHERE map has a spatial resolution of $1 \mathrm{~km}^{2}$, which may not capture all the variability, especially in cities with high population density.

In conclusion, $\mathrm{NO}_{2}$ is associated with an asthma score suggesting that traffic-related air pollution causes asthma symptoms in adults. The stronger effects among those free of asthma and symptoms at baseline may also indicate a role of pollution in the onset of asthma. This needs further investigation. The use of the asthma score offers very attractive alternatives to investigate the aetiology of asthma and the course of this disease in adults.

\section{SUPPORT STATEMENT}

B. Jacquemin benefits from an Inserm post-doctoral fellowship ("poste vert"). The co-ordination of ECRHS II was supported by the European Commission as part of their Quality of Life programme. A full list of bodies that funded the local studies in ECRHS II included in this paper can be found in the Acknowledgements section.

\section{STATEMENT OF INTEREST}

None declared.

\section{ACKNOWLEDGEMENTS}

The following bodies funded the local studies in ECRHS II that are included in this paper.

Albacete, Spain: Fondo de Investigaciones Sanitarias (FIS) (grant code: 97/0035-01, 99/0034-01 and 99/0034-02), Hospital Universitario de Albacete, Consejería de Sanidad. Antwerp, Belgium: FWO (Fund for Scientific Research)-Flanders Belgium (grant code: G.0402.00), University of Antwerp, Flemish Health Ministry. Barcelona, Spain: SEPAR, Public Health Service (grant code: R01 HL62633-01), Fondo de Investigaciones Santarias (FIS) (grant code: 97/0035-01, 99/0034-01 and 99/0034-02) CIRIT (grant code: 1999SGR 00241) "Instituto de Salud Carlos III" Red de Centros RCESP, C03/09 and Red RESPIRA, C03/011. Basel, Switzerland: Swiss National Science Foundation, Swiss Federal Office for Education and Science, Swiss National Accident Insurance Fund (SUVA). Bergen, Norway: Norwegian Research Council, Norwegian Asthma and Allergy Association (NAAF), Glaxo Wellcome AS, Norway Research Fund. Bordeaux, France: Institut Pneumologique d'Aquitaine. Erfurt, Germany: GSF-National Research Centre for Environment and Health, Deutsche Forschungsgemeinschaft (DFG) 
(grant code FR 1526/1-1). Galdakao, Spain: Basque Health Dept. Gothenburg, Sweden: Swedish Heart Lung Foundation, Swedish Foundation for Health Care Sciences and Allergy Research, Swedish Asthma and Allergy Foundation, Swedish Cancer and Allergy Foundation. Grenoble, France: Programme Hospitalier de Recherche Clinique-DRC de Grenoble 2000 no. 2610, Ministry of Health, Direction de la Recherche Clinique, Ministère de l'Emploi et de la Solidarité, Direction Générale de la Santé, CHU de Grenoble, Comite des Maladies Respiratoires de l'Isère. Hamburg, Germany: GSF-National Research Centre for Environment and Health, Deutsche Forschungsgemeinschaft (DFG) (grant code MA 711/4-1). Ipswich and Norwich, UK: National Asthma Campaign (UK). Huelva, Spain: Fondo de Investigaciones Sanitarias (FIS) (grant code: 97/0035-01, 99/0034-01 and 99/0034-02). Montpellier, France: Programme Hospitalier de Recherche CliniqueDRC de Grenoble 2000 no. 2610, Ministry of Health, Direction de la Recherche Clinique, CHU de Grenoble, Ministère de l'Emploi et de la Solidarité, Direction Générale de la Santé, Aventis (France), Direction Régionale des Affaires Sanitaires et Sociales Languedoc-Roussillon. Oviedo, Spain: Fondo de Investigaciones Santarias (FIS) (grant code: 97/ 0035-01, 99/0034-01 and 99/0034-02). Paris, France: Ministère de l'Emploi et de la Solidarité, Direction Générale de la Santé, UCBPharma (France), Aventis (France), Glaxo France, Programme Hospitalier de Recherche Clinique-DRC de Grenoble 2000 no. 2610, Ministry of Health, Direction de la Recherche Clinique, CHU de Grenoble. Pavia, Italy: Glaxo-SmithKline Italy, Italian Ministry of University and Scientific and Technological Research (MURST), Local University Funding for research 1998 and 1999 (Pavia, Italy). Reykjavik, Iceland: Icelandic Research Council, Icelandic University Hospital Fund. Tartu, Estonia: Estonian Science Foundation. Turin, Italy: ASL 4 Regione Piemonte (Italy), AO CTO/ICORMA Regione Piemonte (Italy), Ministero dell'Università e della Ricerca Scientifica (Italy), Glaxo Wellcome spa (Verona, Italy). Umeå, Sweden: Swedish Heart Lung Foundation, Swedish Foundation for Health Care Sciences and Allergy Research, Swedish Asthma and Allergy Foundation, Swedish Cancer and Allergy Foundation. Uppsala, Sweden: Swedish Heart Lung Foundation, Swedish Foundation for Health Care Sciences and Allergy Research, Swedish Asthma and Allergy Foundation, Swedish Cancer and Allergy Foundation. Verona, Italy: University of Verona; Italian Ministry of University and Scientific and Technological Research (MURST), Glaxo-SmithKline Italy.

\section{REFERENCES}

1 WHO. Air Quality Guidelines Global Update 2005, Particulate matter, ozone, nitrogen dioxide and sulfur dioxide. Copenhagen, WHO Regional Office for Europe, 2006.

2 Brauer M, Hoek G, Smit HA, et al. Air pollution and development of asthma, allergy and infections in a birth cohort. Eur Respir J 2007; 29: 879-888.

3 Brauer M, Hoek G, Van Vliet P, et al. Air pollution from traffic and the development of respiratory infections and asthmatic and allergic symptoms in children. Am J Respir Crit Care Med 2002; 166: 1092-1098.

4 Gauderman WJ, Avol E, Lurmann F, et al. Childhood asthma and exposure to traffic and nitrogen dioxide. Epidemiology 2005; 16: $737-743$

5 Schikowski T, Sugiri D, Ranft U, et al. Long-term air pollution exposure and living close to busy roads are associated with COPD in women. Respir Res 2005; 6: 152.

6 Sunyer J, Jarvis D, Gotschi T, et al. Chronic bronchitis and urban air pollution in an international study. Occup Environ Med 2006; 63: 836-843.

7 Zemp E, Elsasser S, Schindler C, et al. Long-term ambient air pollution and respiratory symptoms in adults (SAPALDIA study). The SAPALDIA Team. Am J Respir Crit Care Med 1999; 159: $1257-1266$.
8 Bayer-Oglesby L, Schindler C, Hazenkamp-von Arx ME, et al. Living near main streets and respiratory symptoms in adults: the Swiss Cohort Study on Air Pollution and Lung Diseases in Adults. Am J Epidemiol 2006; 164: 1190-1198.

9 de Marco R, Poli A, Ferrari M, et al. The impact of climate and traffic-related $\mathrm{NO}_{2}$ on the prevalence of asthma and allergic rhinitis in Italy. Clin Exp Allergy 2002; 32: 1405-1412.

10 Garshick E, Laden F, Hart JE, et al. Residence near a major road and respiratory symptoms in US Veterans. Epidemiology 2003; 14: $728-736$

11 Lwebuga-Mukasa JS, Oyana T, Thenappan A, et al. Association between traffic volume and health care use for asthma among residents at a US-Canadian border crossing point. J Asthma 2004; 41: 289-304.

12 Mc Creanor J, Cullinan P, Nieuwenhuijsen MJ, et al. Respiratory effects of exposure to diesel traffic in persons with asthma. $N$ Engl J Med 2007; 357: 2348-2358.

13 D'Amato G, Liccardi G, D'Amato M, et al. Environmental risk factors and allergic bronchial asthma. Clin Exp Allergy 2005; 35: 1113-1124.

14 Gilmour MI, Jaakkola MS, London SJ, et al. How exposure to environmental tobacco smoke, outdoor air pollutants, and increased pollen burdens influences the incidence of asthma. Environ Health Perspect 2006; 114: 627-633.

15 Heinrich J, Wichmann HE. Traffic related pollutants in Europe and their effect on allergic disease. Curr Opin Allergy Clin Immunol 2004; 4: 341-348.

16 Jacquemin B, Sunyer J, Forsberg B, et al. Home outdoor $\mathrm{NO}_{2}$ and new onset of self-reported asthma in adults. Epidemiology 2009; 20: 119-126.

17 Pekkanen J, Sunyer J, Anto JM, et al. Operational definitions of asthma in studies on its aetiology. Eur Respir J 2005; 26: 28-35.

18 Sunyer J, Pekkanen J, Garcia-Esteban R, et al. Asthma score: predictive ability and risk factors. Allergy 2007; 62: 142-148.

19 The European Community Respiratory Health Survey II Steering Committee, The European Community Respiratory Health Survey II. Eur Respir J 2002; 20: 1071-1079.

20 Burney PG, Luczynska C, Chinn S, et al. The European Community Respiratory Health Survey. Eur Respir J 1994; 7: 954-960.

21 Emenius G, Pershagen G, Berglind N, et al. $\mathrm{NO}_{2}$, as a marker of air pollution, and recurrent wheezing in children: a nested casecontrol study within the BAMSE birth cohort. Occup Environ Med 2003; 60: 876-881.

22 Forastiere F, Peters A, Kelly FJ, et al. Nitrogen Dioxide. Air Quality Guidelines: Global Updates 2005. Geneva, World Health Organization, 2006; pp. 331-394.

23 Pattenden S, Hoek G, Braun-Fahrlander $\mathrm{C}$, et al. $\mathrm{NO}_{2}$ and children's respiratory symptoms in the PATY study. Occup Environ Med 2006; 63: 828-835.

24 Beelen R, Hoek G, Pebesma E, et al. Mapping of background air pollution at a fine spatial scale across the European Union. Sci Total Environ 2009; 407: 1852-1867.

25 Long SJ. The Negative Binomial Regression Model. Thousand Oaks, SAGE Publications, Inc., 1997.

26 DerSimonian R, Kacker R. Random-effects model for metaanalysis of clinical trials: an update. Contemp Clin Trials 2007; 28: 105-114.

27 DerSimonian R, Laird N. Meta-analysis in clinical trials. Control Clin Trials 1986; 7: 177-188.

28 Frank P, Morris J, Hazell M, et al. Smoking, respiratory symptoms and likely asthma in young people: evidence from postal questionnaire surveys in the Wythenshawe Community Asthma Project (WYCAP). BMC Pulm Med 2006; 6: 10.

29 Lindstrom M, Kotaniemi J, Jonsson E, et al. Smoking, respiratory symptoms, and diseases : a comparative study between northern Sweden and northern Finland: report from the FinEsS study. Chest 2001; 119: 852-861. 
30 Lindgren A, Stroh E, Montnemery P, et al. Traffic-related air pollution associated with prevalence of asthma and COPD/ chronic bronchitis: a cross-sectional study in Southern Sweden. Int J Health Geogr 2009; 8: 2.

31 Pekkanen J, Sunyer J. Problems in using incidence to analyze risk factors in follow-up studies. Eur J Epidemiol 2008; 23: $581-584$
32 Rage E, Siroux V, Kunzli N, et al. Air pollution and asthma severity in adults. Occup Environ Med 2009; 66: 182-188.

33 Chinn S, Jarvis D, Burney $\mathrm{P}$, et al. Increase in diagnosed asthma but not in symptoms in the European Community Respiratory Health Survey. Thorax 2004; 59: 646-651.

34 Lebowitz MD. Epidemiological studies of the respiratory effects of air pollution. Eur Respir J 1996; 9: 1029-1054. 